\title{
From Tear to Tears
}

\author{
B. Adhisivam • Sunita Namdev $\cdot$ L. P. Nandhini • \\ B. Vishnu Bhat
}

Received: 18 April 2012 / Accepted: 17 September 2012 /Published online: 19 October 2012

(C) Dr. K C Chaudhuri Foundation 2012

To the Editor: A 7-y-old boy presented with redness of right eye following injury to his eye $3 \mathrm{~d}$ earlier. However, the exact nature of injury was not clear. An ophthalmological evaluation revealed right corneal tear and conjunctivitis. He was administered appropriate systemic antibiotics and the corneal laceration was sutured. Four days after the procedure, he was referred to the pediatrician for abnormal behavior and movements. On examination, he was confused and agitated. He had excessive salivation and classical hydrophobia and aerophobia pointing towards a diagnosis of Rabies. On probing the history further, we came to know that the boy had sustained the corneal tear while trying to escape from an attacking stray dog. His neurological status progressively deteriorated and he expired $48 \mathrm{~h}$ later.

There is no cure for rabies once symptoms begin and the disease is almost always fatal. However, there are three reported survivors of human rabies till date [1]. In this case of furious rabies, the history regarding attack by the stray dog was missed and an opportunity to administer rabies immunoglobulin and vaccine was lost. The post exposure prophylaxis can only prevent the disease if given before symptoms start. Therefore, immediate prophylaxis in suspicious cases is essential [2]. On the other hand, even post exposure prophylaxis in rare cases cannot prevent the disease [3]. Probably, the mucosal injury to the eye could have hastened the transmission of virus during the attack by the dog. The proximity of the laceration to the cranial nerves and the suturing of the corneal tear could have also contributed to the rapid disease progression. There are few reports highlighting the risk of rabies in animal bites in and around orbits $[4,5]$. Even though a dog bite victim may present to various specialists depending on the injury, a comprehensive management plan including rabies vaccine and or immunoglobulin should be followed. This tale of corneal tear which unfortunately ended in tears highlights the potential danger of animal attacks on humans and the importance of immediate prophylaxis in suspicious cases. In clinical medicine, there is no substitute for a meticulously taken history!

\section{References}

1. Wiedeman J, Plant J, Glaser C, et al. Recovery of a Patient from Clinical Rabies-California, 2011. MMWR. 2012;61:61-5.

2. Holzer MP, Solomon KD. Rabies prophylaxis after an animal attack that caused a ruptured eye and traumatic cataract: a case report. Cases J. 2009;2:9192.

3. Tabbara KF, Al-Omar O. Eyelid laceration sustained in an attack by a rabid desert fox. Am J Ophthalmol. 1995;119:651-2.

4. Gonnering RS. Ocular adnexal injury and complications in orbital dog bites. Ophthal Plast Reconstr Surg. 1987;3:231-5.

5. Holzer MP, Solomon KD. Bobcat bite injury of the eye and ocular adnexa. Arch Ophthalmol. 2003;121:918-9. 